\title{
Clarity of purpose, focused attention: The essence of excellence
}

\author{
David J. Sugarbaker, MD
}

Teaching trainees how to excel as surgeons is essential to our academic mission. Throughout history, great thinkers from all schools of thought have grappled with the concept of excellence. To my mind, clarity of purpose and focused attention represent the essence of excellence. Today, I will explore this concept in some depth.

Excellence in surgery is under attack. Unprecedented levels of daily distractions erode our ability to identify and hold onto purpose and to focus our attention. The threat to excellence is recognized in other fields, where strong counter measures are being taken. I propose that we must do the same in our field. I will illustrate the elements of an action plan we have found successful in our resident training program. I will tell you a story of a surgeon, who, through the power of his clarity of purpose and focused attention, exemplified excellence in his contributions to his chosen field and did so with meager resources in the most unusual of circumstances.

The dictionary defines excellence as "a state of superiority or eminence"; we might even say, preeminence. However, these static descriptions miss an important nuance-that excellence is not a trait inherited by fortunate individuals. Rather, it must be achieved and maintained through sustained, purposeful, focused action. It is performing a task consistently, as close to the ideal as possible.

More than 2300 years ago, Aristotle defined excellence with reference to this active process. He said, "Excellence is never an accident. It is always the result of high intention, sincere effort, and intelligent execution." How do we break this down? The "high intention" recognized by Aristotle (Figure 1) is not merely a spark that initially ignites the process; it must be clarified and sustained as a singular driving purpose throughout the endeavor. Furthermore, all of one's conscious attention must be exclusively and unrelentingly focused on the physical and intellectual activity required to fulfill that purpose. Indeed, all of these elements must coexist if excellence is to be the result (Figure 2). Maintaining and holding onto our purpose as well as gaining and holding the ability to focus is becoming more and more difficult in the information age.

From Baylor College of Medicine, Houston, Tex

Disclosures: Author has nothing to disclose with regard to commercial support.

Received for publication June 12, 2014; accepted for publication June 13, 2014

Address for reprints: David J. Sugarbaker, MD, Director, The Lung Institute, Chief,

Division of Thoracic Surgery, The Olga Keith Weiss Chair of Surgery, Baylor College of Medicine, One Baylor Plaza, BCM 390, Houston, TX 77030 (E-mail:

DavidSugarbaker@bcm.edu).

J Thorac Cardiovasc Surg 2014;148:764-71

$0022-5223 / \$ 36.00$

Copyright $($ c 2014 by The American Association for Thoracic Surgery

http://dx.doi.org/10.1016/j.jtcvs.2014.06.028

\section{PURPOSE AND FOCUS}

What is meant by the phrase clarity of purpose? Most importantly, it must be a singular purpose in the moment. I tell the residents that the secret to discovering your purpose at a particular moment in time is to close your eyes, open them again, and then see what's directly in front of you. It may be a colleague, it may be a nurse with a question, or it may be a patient or family member. Whatever it is, that's your purpose. Having identified your purpose in the moment, you then need to focus your attention on it and get it done.

Purpose therefore is both the driving force and the direction. Layers of purpose (Figure 3) can lead to a life of habitual excellence and sustained accomplishment. The sharp point of the pyramid is analogous to the narrow focus required for the greatest achievements. These layers of purpose are intertwined. One cannot exist without the other. The more singular and refined the purpose, the easier is its fulfillment. Members of our Association dating back more than 100 years have lived this paradigm and have made tremendous contributions to cardiothoracic surgery.

Purpose and focus are closely interrelated, but subtly different. Once you have determined your purpose, priority shifts to execution of task, and for that, you need focus. Focus involves excluding thoughts unrelated to the task at hand, until the task is completed. Doug Silsbee, author of the book The Mindful Coach, suggests that the inability to clear one's mind of unrelated thoughts is the primary obstacle to achieving excellence in performance. ${ }^{1}$ Focus relies on the ability to subjugate well-practiced, repetitive tasks to the subconscious mind. This leaves the conscious mind unimpeded to be creative and to anticipate and to address quickly any problems that arise. In the OR, we are not thinking about how to tie a knot or how to hold a needle, but instead the larger issues such as the overall conduct and direction of the procedure. Awareness of our physical surroundings is an essential component of focused attention. The surgeon who keeps this awareness in the OR is often first to detect an issue of concern.

Surgery, like golf, is a course in mind training. In paraphrasing the words of Aristotle, the 20th century philosopher, William Durant, has said, "We are what we repeatedly do. Excellence then, is not an act but a habit.", Tiger Woods, the product of endless practice, focused attention, and exclusion of competitive thoughts — as a matter of fact, the exclusion of all thoughts-demonstrates what it takes to achieve excellence every time he executes a flawless golf swing, as he relies upon his practiced ability, unimpeded, to shape the perfect shot. 


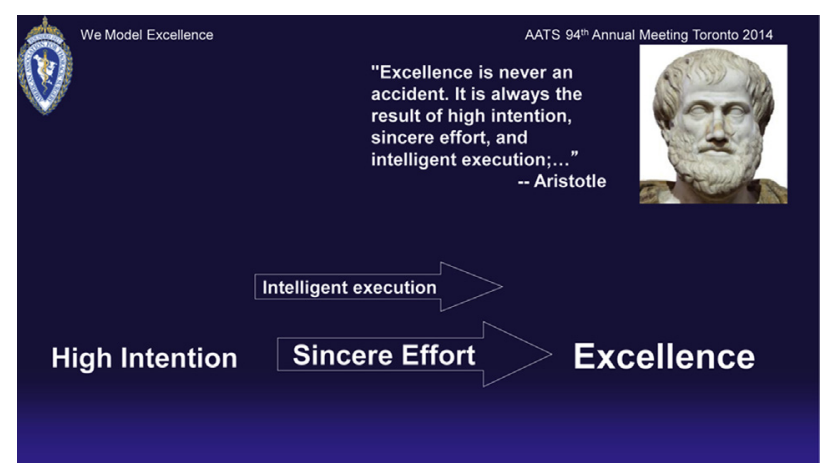

FIGURE 1. Excellence as defined by Aristotle.

Tom Brady-excellence personified-is "the complete package" when it comes to focus, as reflected in his pyramid of purpose (Figure 4). As the New England Patriots quarterback, Tom has set many NFL records for passing and is one of the best in football. His purpose in the moment is to bring his team down the field by executing a series of effective plays. Purpose is what you're going to do, and focused attention is how you get it done. The expression on Tom Brady's face during his games says it all. He is totally focused. He has a general awareness of what's going on around him, of potential tacklers, what's going on downfield, and where his receivers are. His mind, however, is clear of extraneous thoughts. He is never aware of the mechanics of the throw, but he is always aware of the logistics of the field, the position and movement of the defenders, and the motion of his receivers. Purpose and focus combined can produce extraordinary excellence.

\section{THREAT TO THE EXCELLENCE-DISTRACTION}

We all have experienced the constant distractions of the information age: Smartphones, E-mails, social media, an unrelenting barrage of distractions. Today, there is no impediment to feeding your mind. It is the sheer availability of information, literally at our fingertips, that causes us to be distracted.

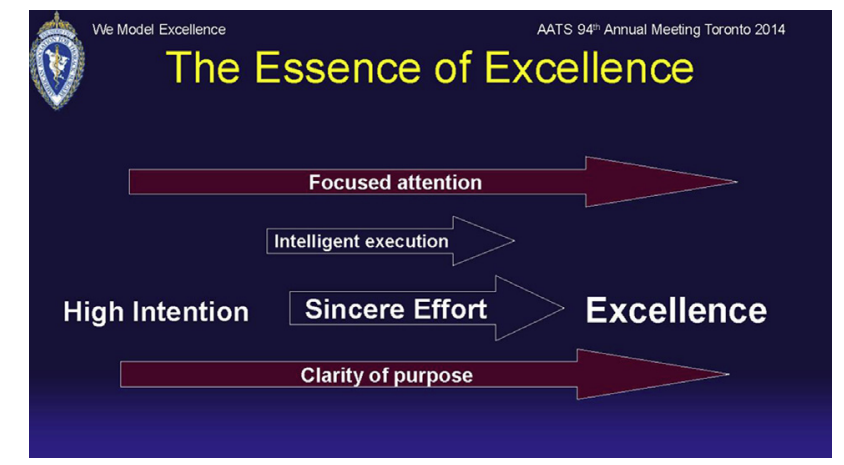

FIGURE 2. Clarity of purpose and focused attention: The essence of excellence.

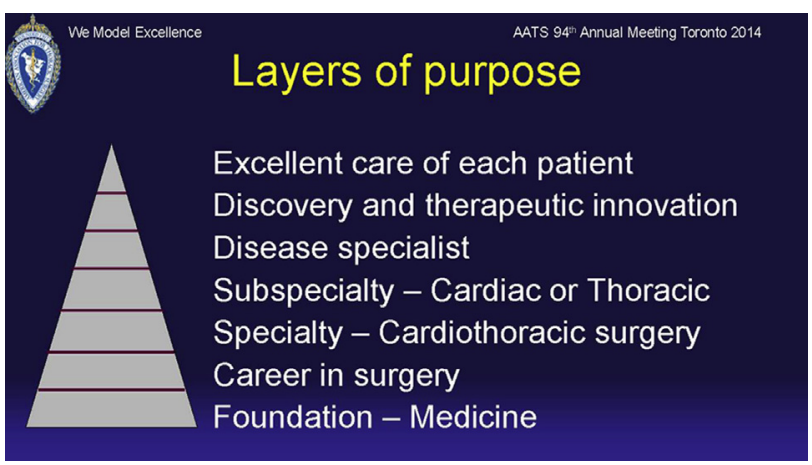

FIGURE 3. A pyramid of purpose.

What happens when we're distracted? We drop out. After the distraction resolves, we're stressed to catch up. It's like going to a movie and "stepping out" to buy some popcorn. When you step out, you drop out. When you come back, you have to ask, "What happened when I was gone?" I don't think we fully recognize how often this happens to us all over the hospital literally hundreds of times per day, as we drop out of a particular situation and then are stressed to regain our orientation.

Residents are no longer insulated from outside distractions when they enter the hospital, as many of us were in the past. Distraction from within and from without, together with the shortened period of time that residents are physically in the hospital, is eroding our ability to perform in an excellent fashion. A destabilization of our workplace culture is occurring. When many of us were training, the surgical culture was inherent to being "in" the hospital. This is no longer the case. These factors affect all of us. We have to recognize what's happening and take action. What is the impact of all this distraction on medical and surgical practice?

Table 1 lists some of the factors impacted by smartphone use in the hospital. The literature is accumulating and is overwhelmingly negative. Note in this table that malpractice cases have been lost when smartphone distractions have been documented in subpoenaed phone records. ${ }^{3}$

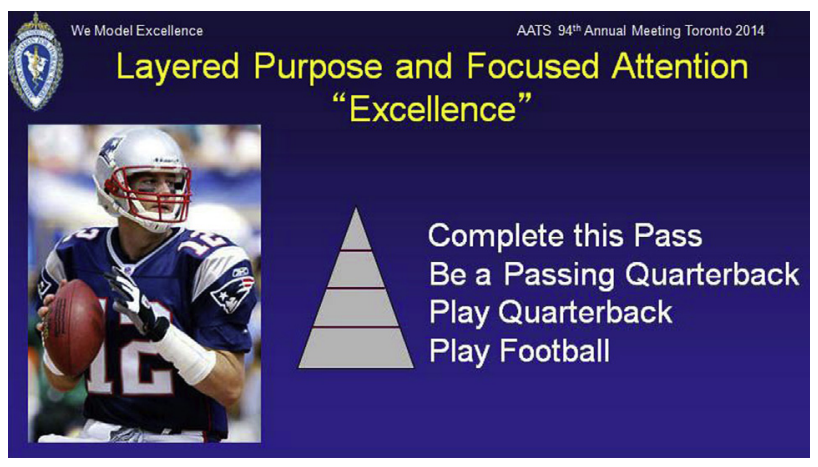

FIGURE 4. Tom Brady—excellence personified! 
TABLE 1. Results of smartphone use in a hospital setting

- Distractions: 12-15 per doctor per hour

- Communication disruption between doctor, nurse, and patient

- Increased reaction time

- Reduced focus resulting in delays

- Inattentional blindness

- Increased error rate

- Reduced cognitive ability

- Medical malpractice evidence

Striking closer to home, in 2010, Smith and colleagues ${ }^{4}$ surveyed 439 perfusionists about their smartphone use during cardiopulmonary bypass. Some of you may recall this publication. It was cited in the New York Times, and the article received a significant amount of attention in the lay press. The survey concluded that $49 \%$ of perfusionists admitted to texting while on bypass, $21 \%$ to E-mailing, and $15 \%$ to surfing the Internet. While only $7 \%$ recognized a negative impact on the case from their own behavior, $34 \%$ recognized it as causing a negative impact when observed in coworkers (Table 2). These data are 4 years old! ${ }^{4}$ This is real. It's not joke. Surgical excellence is at stake.

\section{REDUCING DISTRACTIONS}

What can we learn from the ways that other industries have responded to the challenges of distraction? Piloting an airplane is a situation where distraction and multitasking can have catastrophic consequences. In 1979, NASA identified human error during takeoffs and landings as the primary cause of air transport accidents. ${ }^{5}$ The resulting policy, the Sterile Cockpit, forbade all unrelated discussion between pilots and copilots during takeoffs and landings. ${ }^{6}$ NASA emphasized the importance of codifying expectations and establishing strategies for routine reporting and management of errors. The Sterile Cockpit is a classic example of what it takes to shut out competing information during critical task execution.

"Bounded deferral" is a policy initiated in the computer science industry, which electronically defers digital notifications in the workplace to a designated or "bounded" timeframe. ${ }^{7}$ This practice has been shown to create a calmer, less disruptive work environment. It has been noted to reduce stress, improve the quality of work, decrease error rates, and increase productivity.

Mindfulness is a tool for increasing focus and concentration that has seen a resurgence in recent decades. The concept of mindfulness dates back to ancient Buddhist teachings, when meditation was regarded as the doorway to enlightenment. There was a rebirth of the mindfulness concept in the 1960s and 1970s, when psychologists and other practitioners began to explore the benefits of stress reduction through meditation. Dr Jon Kabat-Zinn, a leader in the field of mindfulness-based cognitive therapy, defines
TABLE 2. Smartphone use by perfusionists during cardiopulmonary bypass: Results of a survey ${ }^{4}$

\begin{tabular}{lr}
\hline Send text messages & $49 \%$ \\
Access E-mail & $21 \%$ \\
Access Internet & $15 \%$ \\
Experience negative effect in themselves & $7 \%$ \\
Perceive negative effect in others & $34 \%$ \\
\hline
\end{tabular}

mindfulness as "paying attention in a particular way; on purpose, in the present moment, and nonjudgmentally." 8,9

Multiple studies have shown that subjects who practice mindfulness can increase their ability to focus and improve their performance. Phrases like "being in the zone" and "automatic, effortless attention to task or flow" began to appear in the psychology, sports, and business literature in the late 1990s. Our society can see and feel the impact of repetitive, extraneous thoughts caused by relentless distractions, and is finding relief through the practice of mindfulness. But what should we do we do in CT surgery? Should we teach mindfulness, as many successful coaches do?

\section{SURGICAL SERVICE ACTION PLAN: FOCAL POINTS}

The problem seems, frankly, overwhelming. How are we to deal with this onslaught? I would propose to restrict those distractions that can be safely reduced. For example, we have a cell phone policy. We have created a system of focal points to command the attention of our residents throughout their time on the service. What are these focal points? They are tasks or times that require the attention of individual team members. They act to transmit information and draw attention to the activities most conducive to learning and the enhancement of care delivery to patients. They are explicit and repetitive communications of codified expectations. They serve as constant reminders of what is expected each day by every member of the team. With all of the distractions that are present in this age, we need to instruct our residents, in a repeated fashion, what it is that they need to focus on while they are in the hospital. We have created a system for doing this. It's almost on autopilot.

We should ask ourselves this question: "Why does anybody need to have a cell phone in the operating room during a case?" We have a cell phone policy for the OR. The goal is to reduce the use of cell phones for personal calls, to eliminate them from the operating room, and instead, to encourage direct and closed loop communications, such that the information transfer is verified. You can ask your hospital administration to support such a policy for all the OR staff. A number of nursing associations and the American College of Surgeons support such a policy, but you'll need to take action. ${ }^{10-12}$

We have a large dry-erase whiteboard on the wall in our operating rooms. The residents are required to fill it out before each case. On the left side of the whiteboard, the 


\section{Expectations and Traditions of the Thoracic Surgical Service for} Fellows, Residents, PAs, and Medical Students

1. PRIORITY SETTING: Each individual on the thoracic team understands that patients and their needs are the top priority $24 / 7$ when a team member is on duty in the hospital or on call. All tasks are to be prioritized in order of importance for completion.

2. ROUNDS: The service will round twice a day, including weekends, and rounds will include an available Pod nurse. A thorough and comprehensive person-to-person sign-out between team residents will occur twice a day with shift change. Additionally, multi-disciplinary rounds will occur daily between junior residents and physician assistants face to face.

3. DOCUMENTATION: It is expected that all adverse events, procedures, transfers, all communications with attendings after hours or other unusual occurrences will be documented in the chart at the time of occurrence. Daily progress notes are required on all patients (no exceptions).

4. COMMUNICATION: All adverse events, procedures, transfers to TICU and ICU, emergent scans, vasoactive drips, unplanned discharges, and unexpected admissions will be communicated to and discussed with the attending staff. The Director of TICU and Chief Residents will conduct comprehensive face-to-face meetings before 7:30 AM, and the Director of TICU and service out fellow and/or on-call fellow will meet daily at 4 PM.

5. OPERATING ROOM EXPECTATIONS: All case assignments will be made by the Service Chief for the residents and fellows by 12 noon the day before surgery, and each resident or fellow will be prepared for their cases including history and procedure review. The history, including TNM stage, will be placed on the board and the ten steps will be outlined by the senior resident or fellow assigned to the case. The case must be discussed with the attending prior to any incision. Site verifications will be followed. The brief operative note will be entered in the chart by the assigned resident immediately after surgery.

6. PATIENT ACCOUNTABILITY: The care of patients outside the ICU is the responsibility of the assigned resident, PA, and fellow. The thoracic team should know the clinical course of ICU patients but the ICU team is held directly accountable for the care while the patient is in the ICU. Senior residents are responsible for the consult service under the direction of the chief residents.

7. RESULTS AND CONSULTS: It is expected that all inpatient scans will be ordered as wet reads and results will be read immediately. It is expected that a senior member of the team will verbally discuss with the attending all consults and scan results the day they are obtained.

8. CHART REVIEW: It is expected that interns and physician assistants will review each assigned patient's chart daily and that chief residents will review charts weekly for proper documentation and daily progress notes.

9. DISCHARGES: All discharges, including dictations, prescriptions and plans, will be completed before rounds on the day of discharge (no exceptions). Discharge medications and instructions must be confirmed with the TICU Director.

10. CONFERENCES: It is expected that all thoracic teams members will attend Wednesday (CT Resident meeting and pathology/radiology/surgery) and Friday (Quality Assurance) conferences when at all possible. Members are further encouraged to attend Thursday (pulmonary/radiology and Dr. McNamee's interesting case rounds in the ICU) conferences. The service chief resident is expected to organize weekly Saturday morning teaching rounds with an Attending of their choice.

11. PROFESSIONALISM: The Thoracic Surgical Resident Team values professionalism as being of utmost importance in the career development of the resident staff. The Thoracic Surgical Service seeks to maintain the highest standards of professionalism. Residents and fellows are expected to wear white coats at all times on the ward and adhere to hospital guidelines on dress. It is expected that all team members will remain polite and professional at all times.

12. CELL PHONE USE: The use of cell phones for personal calls and texts while in patient areas is strongly discouraged. Cell phone use in the operating room or during rounds and conferences is restricted to emergency calls only. Residents should sign out during operative procedures. Emergency reports to the $O R$ should be done in person by resident staff. Closed loop communication standards will be followed. The verbal communication of patient status and information is always preferred. Cells phones will be on vibrate or silent mode while in the hospital.

FIGURE 5. The pledge read every Friday by a resident physician on the clinical team.

residents record a brief patient history including pertinent lab and radiologic data. To the right, the residents write their idea of what the 10 steps of the operation should be from their preparation the night before. The exercise provides a focal point, a need for them to focus, and a need for them to prepare. It also provides an excellent opportunity to teach.

We reinforce and teach essential skills like communication and how to organize a patient presentation. The template for patient presentations is displayed in the clinic. Each resident is given a pocket-sized version of these expectations for daily use and future reference. ${ }^{13}$

The document, "Expectations and Traditions of the Thoracic Surgical Service" (Figure 5), is truly a foundational document. It codifies our core values and expectations for the conduct of the Thoracic Surgery Service. The residents call it "the Pledge." Every week at our Q/A meeting, a resident stands up in front of the entire group and reads this document out loud. It's a method that has been used in the context of providing 5-star hotel service. I first witnessed it in California in 2003. With the time change, I was up early. It was about 4 o'clock in the morning and I saw a member of the hotel staff reading from a list of expectations to the entire hotel staff in the lobby as the staff read along on their own copies. When I inquired of the manager about what I had seen, he explained that by doing this, they were creating a stable work culture in the hotel. Having the resident staff recite this document weekly has had a very positive impact on the efficiency and quality of patient care that is delivered on our service. It is a superb teaching tool as well. We also use the fulfillment of these expectations in making objective resident evaluations. 


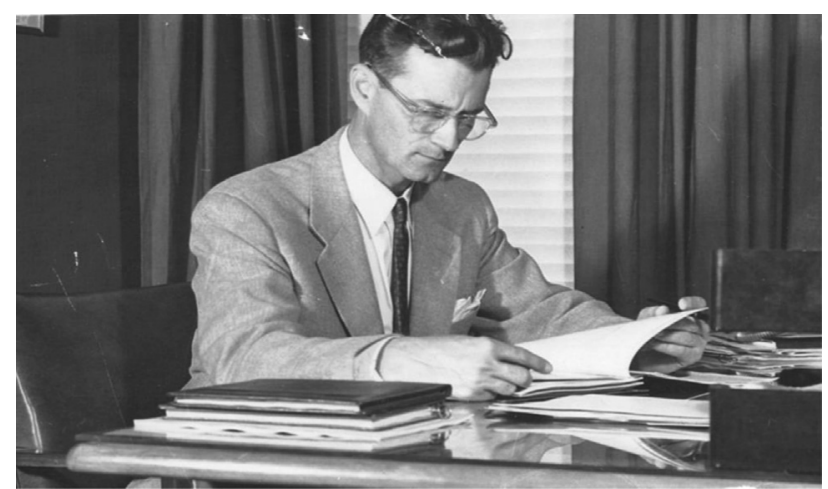

FIGURE 6. Everett D. Sugarbaker, MD, 1910-2001.

\section{PURPOSE AND FOCUS PERSONIFIED}

I would like to tell you the story of Everett D. Sugarbaker, my father. You can see on his face (Figure 6) a certain intensity and a certain intention. His life was one of high intention. He had a clarity of purpose that was, well, quite amazing. His ability to focus his attention despite an avalanche of continuous distraction was phenomenal. His pyramid of purpose had a very sharp point (Figure 7). He grew up in the midst of the Great Depression and worked his way through college and medical school. His father Evert and his mother Anna were Dutch immigrants. They came to this country with nothing.

Everett Sugarbaker found his life's purpose in medicine. He is a stellar example of the paradigm for excellence I have explored with you today. Let's follow the development of his pyramid of purpose as his career progresses. He attended Cornell Medical College. As you can see in this photograph taken in the gross anatomy lab during his first year of medical school, the laboratory attire was quite different in that day (Figure 8). He did an internship at the Henry Ford Hospital in Detroit because it paid \$125.00 a month, and that salary allowed him and my mother to get married. He continued to build his foundation of purpose. Then it was on to the Memorial Hospital in New York City, the first cancer hospital in the United States. He worked at this prestigious institution, founded by James Ewing and financed

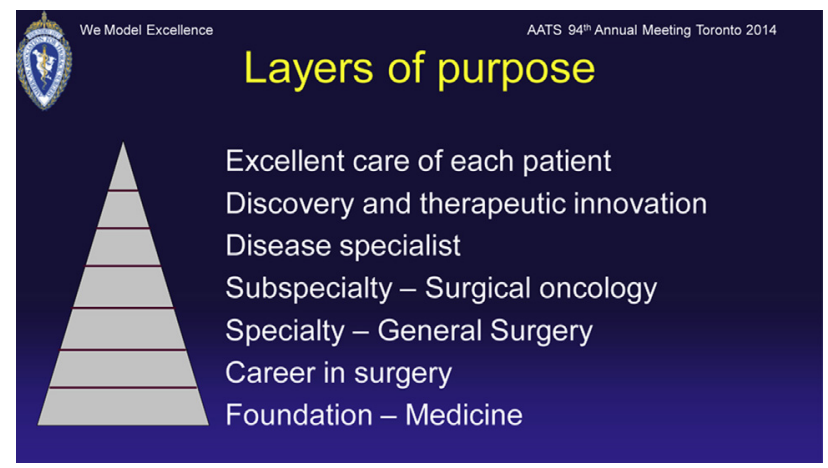

FIGURE 7. Pyramid of purpose of Everett Sugarbaker, MD.

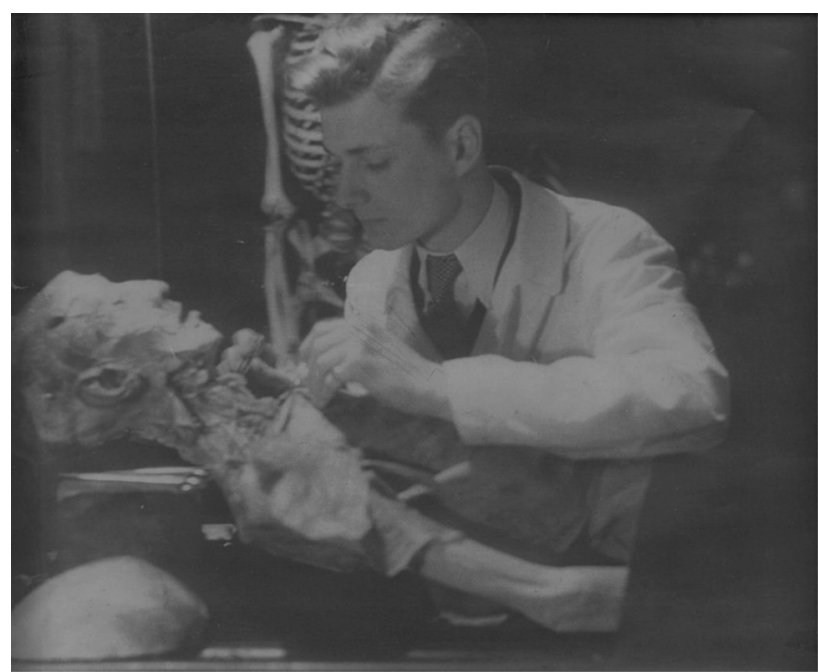

FIGURE 8. Everett Sugarbaker, MD, as a first-year medical student, gross anatomy lab, Cornell Medical College.

by John D. Rockefeller, from 1935 to 1939 . It was the academic center for surgeons interested in cancer, and it had been established specifically for the treatment of cancer and allied diseases. His time there was marked by intense academic productivity. He spent hundreds of hours in the record room and published many seminal papers.

He, along with many of his fellow residents at Memorial Hospital, went on to pioneer cancer surgery all over the United States (Figure 9). Together, they founded the James Ewing Society which later became the Society of Surgical Oncology. He left Memorial to accept an appointment as Chief of Surgery at the National Cancer Institute (NCI) in Baltimore, but the lack of clinical activity at the NCI soon caused him to look elsewhere to utilize his surgical training.

Where did he go? Despite being a lifelong East Coaster, he took a position as chief of staff and chief of surgery at the

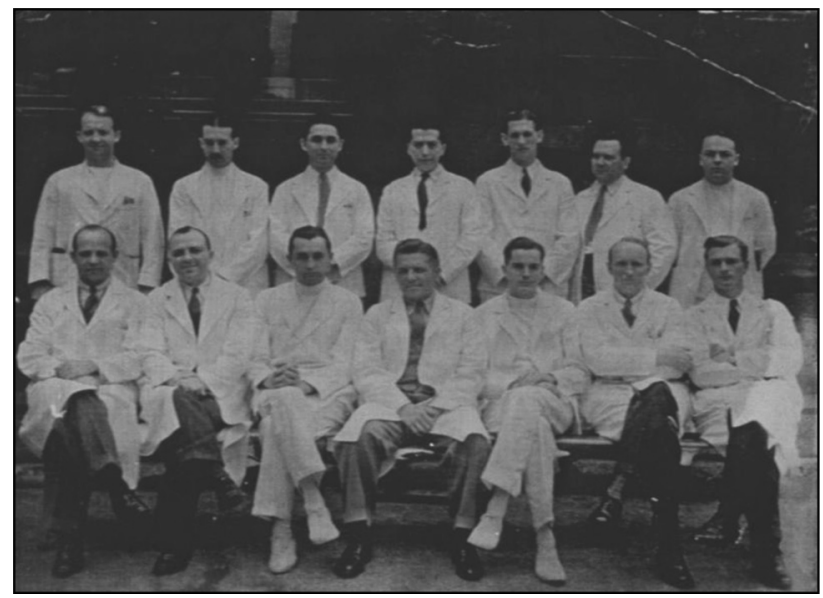

FIGURE 9. First row, far right, Everett D. Sugarbaker, MD, with fellow residents at Memorial Hospital, New York. 

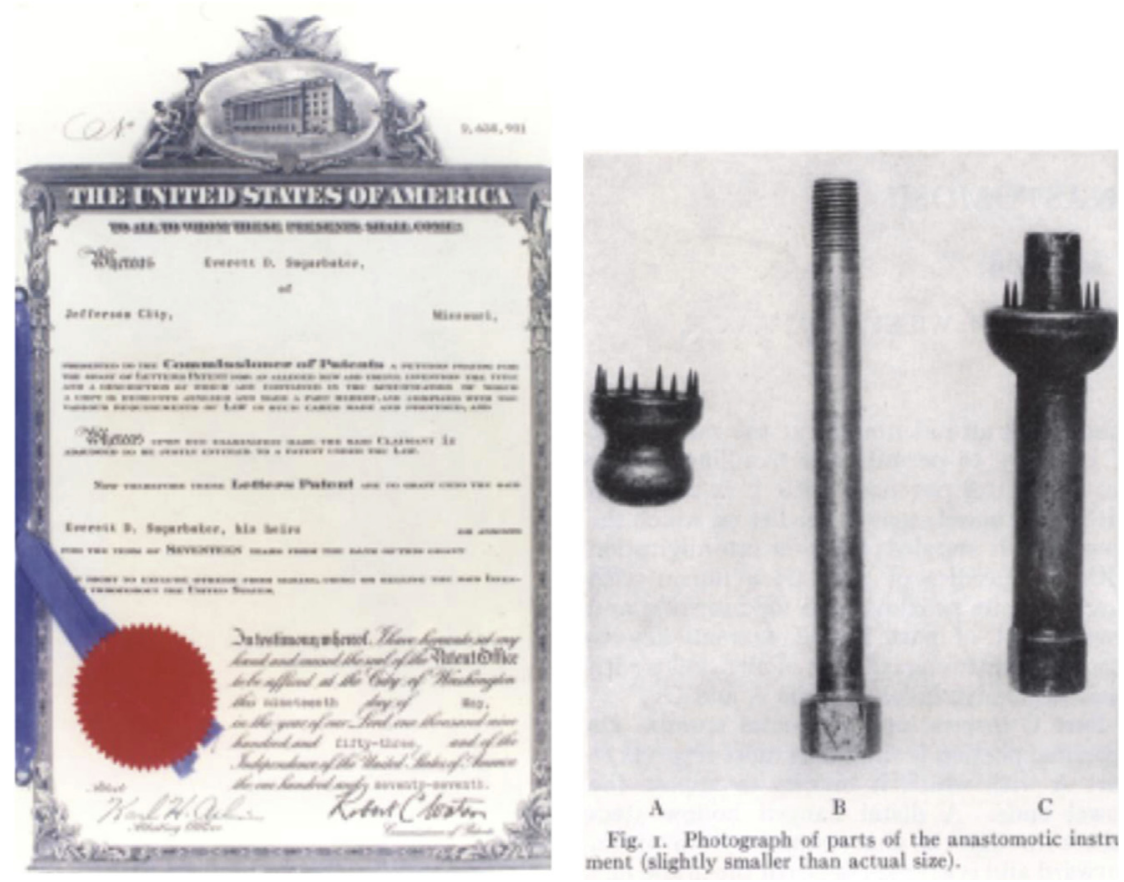

FIGURE 10. US patent issued in 1953 for rectocolic anastomosis instrument.

newly built Ellis Fischel State Cancer Hospital in Columbia, Missouri. Columbia was a small town on the edge of the Ozark Mountains. This was at a time when the town was characterized by late 19th-century culture. He was the first surgical oncologist to practice west of the Mississippi, according to a recently published book on the history of Missouri medicine. ${ }^{14}$ His associates in New York told him Missouri was a primitive place and he would never be able to do large or complex surgical cases, citing lack of support. They pronounced his academic career to be definitely over.

The Ellis Fischel State Cancer Hospital had been established by the Missouri State Cancer Commission to serve indigent cancer patients. My father had a knack for recruiting excellent individuals, such as Dr Lauren Ackerman, who would go on to write the first textbook of surgical pathology, ${ }^{15}$ and Dr Juan Del Regato, the radiation oncologist who trained with Marie and Pierre Curie and who was a pioneer as well. The Ellis Fischel became a focus for surgical training of residents and fellows from all over the country. Together with his staff, he published over 100 papers over the next 10 years. He built teams and hospital infrastructure and established a capable blood bank.

So what about performing big and complex surgery? Was that, as his colleagues had predicted, impossible? The pioneering and seminal paper on the technique of hemipelvectomy entitled "Disarticulation of the innominate bone for malignant tumors of the pelvic parietes and upper thigh," 16 published in Surgery, Gynecology and Obstetrics in 1945, demonstrated that indeed that was not the case. He had taken his superb surgical training with him, and he continued to build his layers of purpose as a specialist in surgical oncology despite his geographic location.

With a growing family to feed and care for, he moved his practice 35 miles south to Jefferson City where he established the Sugarbaker Tumor Clinic in this town of about 20 thousand people. Jefferson City is located on the Missouri River, on the Ozark Plateau, next to the historic Lewis and Clark Trail. He equipped the clinic with its own radiation therapy machine, radiology equipment, as well as minor surgery procedure rooms. Patients came from all over the Ozark Hills and surrounding states. The waiting room was packed on clinic days. It was standing room only on the front porch. As a kid I loved to be around on clinic days because the energy was so inspiring. I can vividly recall the white sign with red letters that hung on the column on the front of the clinic since the day it opened. It said "The Sugarbaker Tumor Clinic for cancer and allied diseases."

My father was troubled, as were other surgical oncologists, over the number of times he was unable to perform a low anterior resection, which could spare the patient a permanent colostomy. The challenge set his creative mind to work. He designed what he called "the gadget." He worked with an elderly German machinist who had a one-man shop located near the train station in Jefferson City. The result was a rectal anastomotic instrument, which was commercialized by Sklar Surgical Instruments company. ${ }^{17}$ Using 


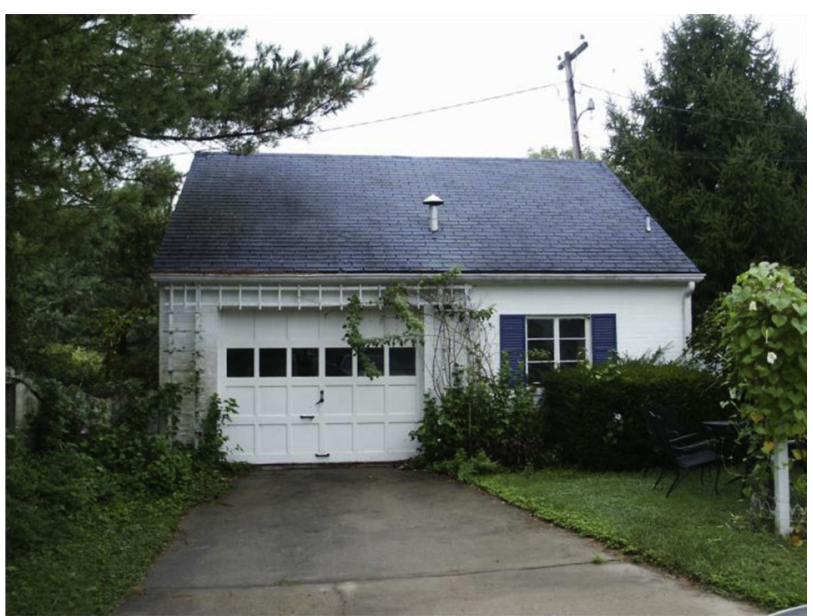

FIGURE 11. Garage next to Sugarbaker home housing the Wistar rat colony.

this gadget, he was able to save the lower sphincter in a large number of patients. The alternating pin locking mechanism used in his device was similar to the design used in the endto-end anastomosis stapler, which came much later. The US patent for this device was issued in 1953 (Figure 10).

His love of tumor biology and his quest for answers, particularly regarding the mechanism behind metastatic spread of cancer, motivated him to build a laboratory in the garage (Figure 11) that was situated right next to our home. In this laboratory, with the technical assistance of his sons and daughters, he maintained a colony of white Wistar rats, which were regularly flown into Jefferson City from the Charles River Laboratories in Boston, Massachusetts. He developed and maintained 3 experimental tumor lines by retransplanting the cells every 2 weeks into fresh rats. He was very interested in understanding why

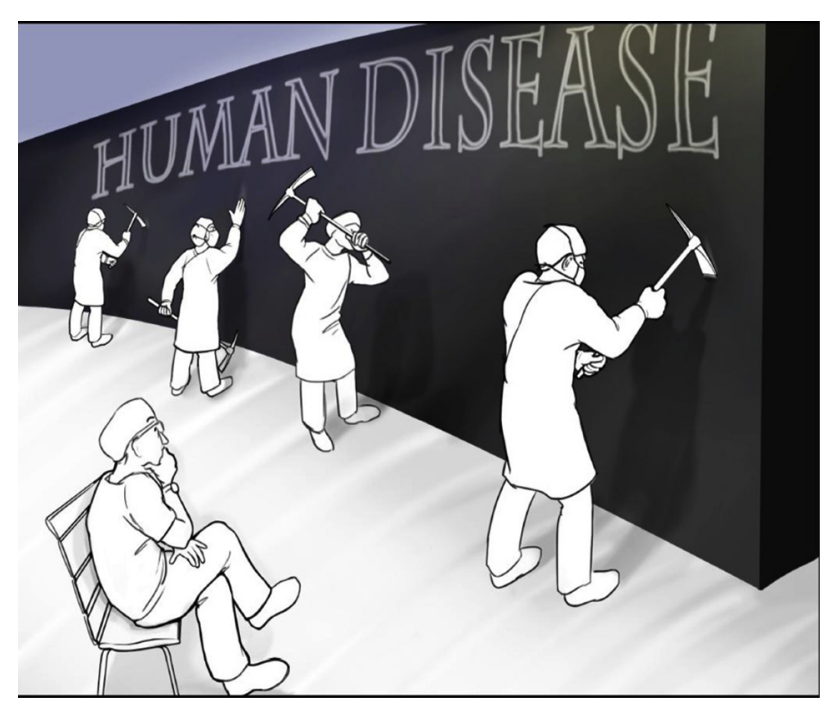

FIGURE 12. Granite wall of human disease.

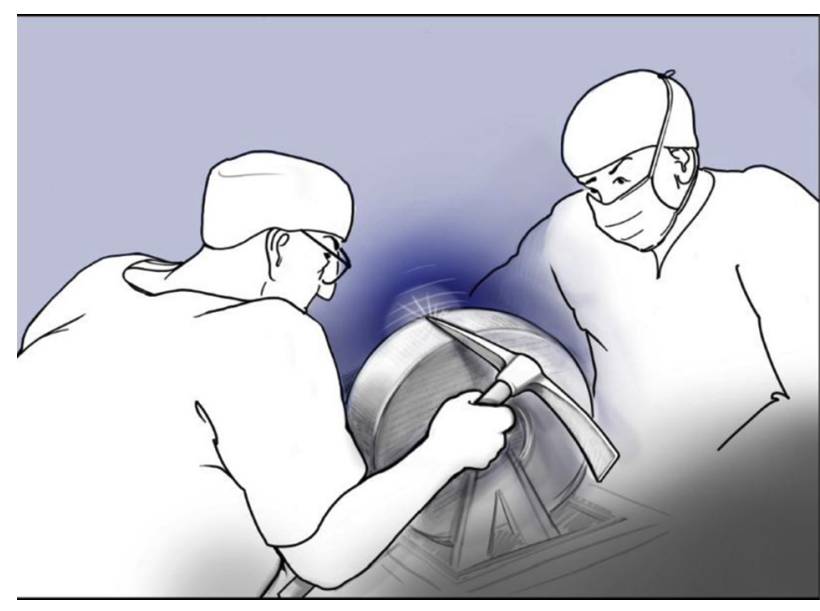

FIGURE 13. Turning the axe around, he sharpened the blade to an extremely fine point.

certain tumors were differentially distributed to different parts of the body. He free-hand injected emulsified tumor cells from 3 different tumor lines into the left ventricle of normal rats. He then carefully autopsied the rats and described the different metastatic patterns.

He recorded the organ distribution of gross metastases found in 46 rats that underwent free-hand left ventricular puncture with emulsified tumor cells and he established that each of these 3 tumors had a distinct pattern of metastatic spread. The paper entitled "The Organ Selectivity of Experimentally Induced Metastases in Rats" was published in Cancer, the most prestigious cancer journal of its time. ${ }^{18}$ He published his paper from Jefferson City, Missouri; from the laboratory located in our garage. The paper has been cited multiple times in recent years, and his work, which established the so-called "seed-soil theory of metastases," is

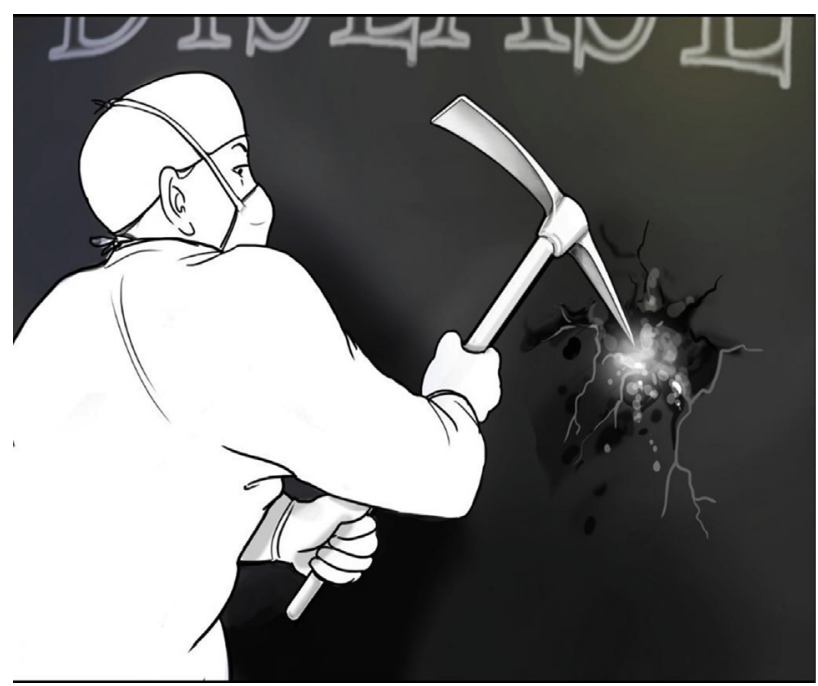

FIGURE 14. With a sharp, focused point the ambitious young surgeon began to produce the first signs of progress against human disease. 
recognized as one of the foundational contributions to the understanding of metastatic disease.

The story you've just heard is a perfect example of a pyramid of purpose that, when combined with focused attention, produced a career marked by excellence and accomplishment. I am reminded of my father's words. "David," he said, "wherever you go, it's $90 \%$ you and $10 \%$ where you are." This story demonstrates that Clarity of Purpose and Focused Attention are indeed the essence of excellence.

Excellence in our specialty now and in the future is in our hands. My message, today, is that excellence in the practice of surgery is threatened. The ability to formulate a clear purpose and hold focused attention is becoming more and more difficult in the information age. Electronic distractions, which are ever increasing, are having a negative impact on resident training. These distractions are making the conduct of an orderly surgical service more and more difficult to achieve.

We can take countermeasures. You have seen and heard some of the ways by which we can effectively begin to do this. By using explicit repetitive communication of codified expectations in our resident training programs, we can enhance resident training and improve patient care. These strategies help to stabilize our workplace culture. The portfolio of documents that we've created for our program can be downloaded from the Webcast of the 2014 meeting at the AATS Web site (www.aats.org). ${ }^{13}$ I'm sure that many of you will make changes in them to fit your own institution, but the methodology, in our experience, is very effective in helping the residents stay focused on their responsibilities and in their efforts to learn. The response from our residents has been very positive.

\section{EPILOGUE}

\section{Parable of the Ambitious Young Surgeon}

An ambitious young surgeon wanted to make progress against human disease through his own career. He approached a large wall made of black granite labeled "human disease" (Figure 12). He picked up his pick axe and began swinging at the wall next to many other young surgeons who were doing the same. He was discouraged, however, because despite his effort there was no dust, no progress. He then became aware of an older surgeon, his soon-to-be mentor, sitting nearby, and he queried him as to how he should proceed. The surgeon took the pick axe in his hands and turned it around to the sharper side. $\mathrm{He}$ took out a grinding wheel and sharpened it to a fine point
(Figure 13). He said to the young surgeon, "Take this and try it again." With only a few swings, the young surgeon saw dust begin to fly and soon began to make progress (Figure 14).

The moral of the story is clear. The ambitious young surgeon had a purpose: He wanted to make progress against human disease, but he was going about it the wrong way. Aware of the older surgeon when others weren't, he approached him for advice. With mentoring, he further sharpened and defined his purpose, focused his efforts, and only then began to make progress in his field.

I'd like to thank you for the privilege of serving the American Association for Thoracic Surgery as your 94th president, and I thank you for your kind and focused attention this morning.

\section{References}

1. Silsbee J. The mindful coach. New York: Jossey-Bass; 2000.

2. Durant W. The story of philosophy: the lives and opinions of the world's greatest philosophers. New York: Simon \& Schuster; 1926.

3. Gill PS, Kamath A, Gill TS. Distraction: an assessment of smartphone usage in health care work settings. Risk Manag Healthc Policy. 2012;5:105-14.

4. Smith T, Darling E, Searles B. 2010 Survey on cell phone use while performing cardiopulmonary bypass. Perfusion. 2011;26:375-80.

5. Cooper G, White M, Lauber J. Resource management on the flightdeck. Proceedings of a NASA/industry workshop. Moffett Field: NASA-Ames Research Center 1980. NASA Publication No. CP-2120.

6. Helmreich RL, Merritt AC, Wilhelm JA. The evolution of crew resource management training in commercial aviation. Int J Aviat Psychol. 1999;9:19-32.

7. Cutrell E, Czerwinski M, Horvitz E. Notification, disruption and memory: effects of messaging interruptions on memory and performance. Human-Computer Interaction-Interact '01. 2001:263-9.

8. Kabat-Zinn J, Lipworth L, Burney R. The clinical use of mindfulness meditation for the self-regulation of chronic pain. J Behav Med. 1985;8:163-90.

9. Kabat-Zinn J. An outpatient program in behavioral medicine for chronic pain patients based on the practice of mindfulness meditation: theoretical considerations and preliminary results. Gen Hosp Psychiatr. 1982;4:33-47.

10. American College of Surgeons. Cell phone policy. 2008. Available at: http:// www.facs.org/fellows_info/statements/st-59.html. Accessed May 1, 2014.

11. American Association of Nurse Anesthetists. Smartphone policy. Available at: http://www.aana.com/resources2/professionalpractice/Documents/PPM\%20PS $\% 202.18 \% 20$ Mobile\%20Device\%20Use.pdf. Accessed May 1, 2014.

12. Cell phones in OR. The OR Manager. Available at: https://www.ecri.org/ Documents/Reprints/Cell_Phones_are_Everywhere_but_do_they \%20Belong in_the_OR\%280R_Manager\%29.pdf. Accessed May 1, 2014.

13. AATS handouts. Available at: http://aats.org/multimedia/files/annualmeeting/2014/ Presidential-Address.pdf. Accessed May 15, 2014.

14. Humphrey L. Quinine and quarantine: Missouri medicine through the years. Columbia: University of Missouri Press; 2013:80-1.

15. Ackerman L. Surgical pathology. St Louis: C.V. Mosby; 1953.

16. Sugarbaker E, Ackerman L. Disarticulation of the innominate bone for malignant tumors of the pelvic parietes and upper thigh. Surg Gynecol Obstet. 1945;81: 36-52.

17. Sugarbaker ED, Wiley HM. Rectocolic anastomosis; a simplified method. Surg Gynecol Obstet. 1951;93:597-605.

18. Sugarbaker ED. The organ selectivity of experimentally induced metastases in rats. Cancer. 1952;5:606-12. 